\title{
Case report: emergency treatment of near-fatal acute asthma
}

\author{
Dario Lo Cigno, Federico Vischia, Antonio Sechi \\ SC MeCAU e PS, Ospedale Torino Nord Emergenza San Giovanni Bosco, Torino
}

\section{SINTESI}

L'asma bronchiale è una malattia respiratoria cronica caratterizzata da sintomi respiratori di gravità variabile che possono condurre all'insufficienza respiratoria. La NIV è una metodica di supporto respiratorio utilizzata da anni con successo nella BPCO riacutizzata. Tuttavia,

A 43-years old male was admitted to our emergency department complaining of severe dyspnea. He was assigned red code and was admitted directly in shock room. The patient had hystory of asthma (but he used rarely bronchodilators) and he was a drug addict.

The patient was conscious but restless, he was unable to lie down, showed signs of respiratory distress with accessory muscle use, he was unable to speak just a single word. Respiratory sounds were diminished on both lungs with severe diffuse and bilateral wheezing. There were no other significative findings to the physical examination. Vital signs were as follows: arterial pressure $145 / 80 \mathrm{mmHg}$, heart rate 140 bpm, $\mathrm{SpO}_{2} 70 \%$ in air. $\mathrm{T} 36,8^{\circ} \mathrm{C}$, respiratory rate $40 / \mathrm{min}$. Promptly, $\mathrm{O}_{2}$ with reservoire mask was administered; a central venous line was placed in femoral vein because periferal veins were not available. The BGA showed $\mathrm{pH} 7.14 \mathrm{pCO}_{2}$ $77 \mathrm{mmHg}, \mathrm{pO}_{2} 44.2 \mathrm{mmHg} \mathrm{HCO} 28.4 \mathrm{mEq} /$, lactate 2.8 $\mathrm{mg} / \mathrm{dl}$.

The patient was administered nebulized salbutamol, iv metilprednisolone, iv aminophilline, nebulized and im epinephrine, iv magnesium sulphate. Because of the severe respiratory distress and the acute respiratory acidosis, we started also noninvasive ventilation by means of a Draeger Evita 4 ventilator with a facial mask setted as follows: PEEP $0 \mathrm{cmH} 20$ (ZEEP) + ASB $8 \mathrm{cmH} 20, \mathrm{FiO}_{2}$ 100\%. The patient well tolerated noninvasive ventilation. A chest X-ray showed bilateral lung inflation without pulmonary thickening or pleural effusion; cardiovascular profile was normal. (Figure 1).

Blood tests showed slightly elevated neutrophil count (WBC $\left.16730 / \mathrm{mm}^{3}\right)$ while C-reactive protein was normal $(<0,5 \mathrm{mg} /$ il suo uso non è ancora ben definito nelle riacutizzazioni di asma bronchiale. In questo articolo presentiamo la nostra esperienza di un caso di riacutizzazione asmatica quasi-fatale trattata con successo in DEA mediante NIV, ed esaminiamo le evidenze scientifiche al riguardo.

dl). After 30 minutes of NIV another BGA was performed: pH 7.22, $\mathrm{pCO}_{2} 66 \mathrm{mmHg} \mathrm{pO}_{2} 453 \mathrm{mmHg} \mathrm{HCO} 327.8$ $\mathrm{mEq} / \mathrm{l}$. Clinically, the patient showed less wheezing and vitals signs were also improving: $\mathrm{SpO}_{2} 100 \%$ during NIV with $\mathrm{FiO}_{2}$ 1.0, HR 120 bpm R, PA 130/75 mmHg RR 28/min. So, we continued to ventilate the patient as described, reducing $\mathrm{FiO}_{2}$ from 1.0 to 0.5 because of the excellent $\mathrm{pO}_{2}$.

After 3 hours of NIV BGA was further improved (pH 7.37, $\mathrm{pCO}_{2} 45 \mathrm{mmHg}, \mathrm{pO}_{2} 156 \mathrm{mmHg}, \mathrm{HCO} 325.4$ ); the patient was therefore transferred in medical ward, where he was administered only $\mathrm{O}_{2}$-therapy with nasal cannula, bronchodilators and steroids. He did not need ventilation anymore, and he was discharged the sixth day after admission.

Noninvasive ventilation is an effective respiratory support technique, mainly in respiratory insufficiency due to COPD

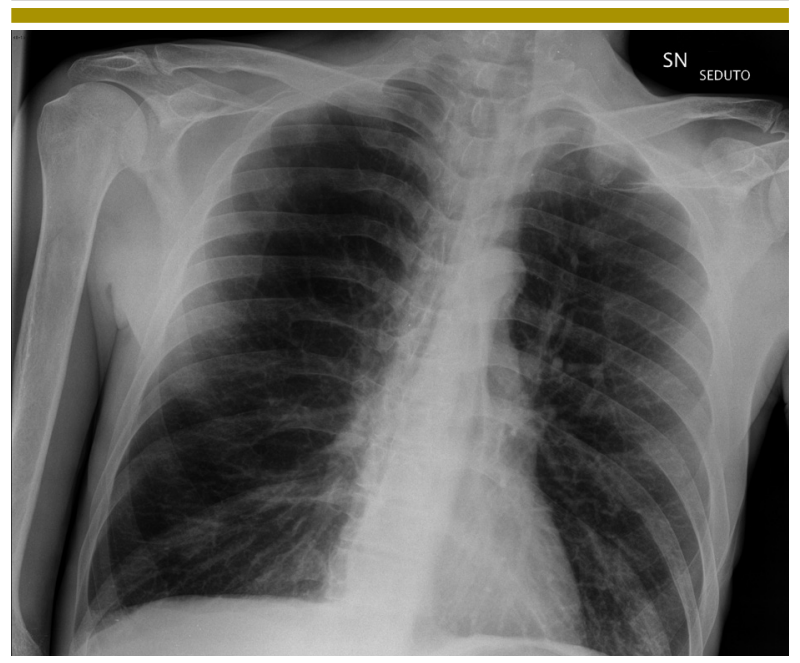

Fig. 1 - The patiens' Chest $\mathrm{x}$-Ray showing lung inflation. 
exacerbations. There is increasing evidence that in patient with COPD exacerbation NIV improves blood gas tests while reducing mortality, respiratory workload, and endotracheal intubation needs ${ }^{1,3,4,5,6}$.

Asthma is an inflammatory disease affecting small airways associated with airway hyperresponsiveness, reversible airflow limitation, and respiratory symptoms variabile from dyspnea to status asthmaticus ${ }^{2}$. Asthma shares with BPCO some pathophysiologic features like bronchial airflow limitation, increased respiratory workload and increased residual functional capacity, due to air trapping ${ }^{2}$. However, in asthma these features are mostly reversibile with bronchodilators, while in COPD they are not ${ }^{2}$.

Another difference between asthma and COPD is that in latter the airway obstructed are the distal, smallest and more collapsible, while in the former the airway obstructed from mucus are the proximal ones ${ }^{11}$. Besides, in asthmatic patients the airways are stiffer than in COPD patients; so, while airway resistance is higher than in COPD, the dynamic collapse during exhalation may be lower ${ }^{11}$. Therefore, in asthmatic patients there is a higher risk of increasing air trapping by ventilating the patient with external-PEEP without knowing his auto-PEEP ${ }^{11}$. This observation seems to be confermed by some pathophysiologic studies and explains why the authors recommend to ventilate asthmatic patients with zero-PEEP11,12,13.

From a clinical point of view asthma exhacerbations may be divided as follows:

- mild: the patient can walk, lie down and speaks almost normally; he may be agitated and respiratory rate is < $30 / \mathrm{min}^{14}$

- moderate: the patient can not lie down, can say just one sentence; he is agitated, respiratory rate is mildly increased but $<30 / \mathrm{min}^{14}$;

- severe: the patient sits up and leans his arms on the table, he is able to speak only a few words, is agitated and respiratory rate is severely increased $(>30 / \mathrm{min})$. When the patient became confuse or disoriented, cardiac arrest is oncoming $^{14}$.

In status asthmaticus, death follows asphyxia due to worsening respiratory distress ${ }^{2}$. This is caused by air trapping and decreased ventilation that are followed by hypoxia, hypercapnia and acidosis ${ }^{2}$. Often, in adults, viral upper airways infection are triggers for asthma exhacerbations; however, other known triggers are psychosocial stress, exercise, and allergens ${ }^{2}$.

Medical treatment of severe asthma and status asthmaticus is an important challenge for emergency physicians because therapy depends on the patient and on the degree of airflow obstruction. Asthma management includes':

- $\mathrm{O}_{2}$-therapy, that should be administered by any means until reaching $\mathrm{pO}_{2}>60 \mathrm{mmHg}$ and $\mathrm{SpO}_{2} 92 \%$; high $\mathrm{O}_{2}$ flux may be detrimental in hypercapnic patients ${ }^{2}$.

- Bronchodilators, that acts on bronchial smooth muscle reducing bronchial obstruction ${ }^{2}$ :
1. beta-agonists (mainly short-acting inhaled, like salbutamol); they should be administered by pressurized metered-dose inhalers with spacer; as an alternative, they can be administered by nebulization in $\mathrm{O}_{2} 6-8$ $1 /$ min. Oral or iv way of administration are not more effective, while they increase the risk of side effects (mostly arrhythmic). In severe asthma exhacerbation, beta-agonists therapy should be repeated (2.5-5 mg per dose) every 10-20 $\mathrm{min}^{2}$;

2. anticholinergics. The most effective is inhaled ipratropium bromide administered $80 \mathrm{mcg}$ per dose by means of pressurized metered-dose inhalers with spacer. It can be repeated every $10 \mathrm{~min}^{2}$.

- Corticosteroids, that act reducing airway inflammation and should be administered by 2 different ways ${ }^{2}$ :

1. systemic corticosteroids, may be administered orally or iv; the recommended dose is 40-60 $\mathrm{mg}$ prednisone or methylprednisolone $e^{2}$. Probably, higher dose (> 160 mg methylprednisolone) are equally effective than lower doses ${ }^{2}$;

2. inhaled corticosteroids, that seems to increase bronchodilator's effects ${ }^{2}$.

- Theophylline. As monotherapy, theophylline is inferior to beta-agonists; however, it can give an additional bronchodilator effect in association to beta-agonists. High incidence of side effects (like tachyarrhytmias) means that it may be useful only in severe asthma. Recommended loading dose is $6 \mathrm{mg} / \mathrm{kg}$ iv in 30 minutes followed by $0.5 / \mathrm{kg} / \mathrm{h}$ until reaching theophylline blood levels 8-12 $\mathrm{mcg} / \mathrm{ml}^{2}$.

- Magnesium sulphate: a safe and cheap medication with some bronchodilator effect. However, 3 recent metaanalysis did not confirm its clinical effectiveness ${ }^{2,16,17,18}$.

- Helium. When bronchial obstruction increases, airway flow becomes turbulent, so increasing airway resistance. Replacing nitrogen with helium (that is more viscous but equally inert) can reduce airway flow turbulence, so decreasing airway resistance. The benefits of heliox (helium + oxygen) are lost when large amounts of supplemental oxygen are introduced into the heliox breathing circuit $\left(\mathrm{FiO}_{2}>30 \%\right.$ needed to maintain $\mathrm{pO}_{2}>60$ $\mathrm{mmHg})^{2}$.

- Other therapies (leukotriene antagonists, antibiotics) are not effective per se but may be useful in some selected case ${ }^{2}$.

Theoretically, COPD and asthma should respond to non-invasive ventilation in the same way. However, while in COPD the efficacy of non-invasive ventilation is indisputable, there is not yet an agreement on using non-invasive ventilation in asthma.

In fact, some studies demostrated that NIV can reduce the need for endotracheal intubation ${ }^{1}$. In a study carried out in 2003, 30 patients were randomized in 2 groups: 15 treated with only conventional therapy, 15 treated with conventional therapy and NIV ${ }^{7}$. After $3 \mathrm{~h}$ both groups showed improve- 
ment in lung function tests (FEV1, FVC, PEF) and BGA parameters, and decreasing in respiratory rate ${ }^{7}$. However, these parameters improve more significantly in patients treated with non-invasive ventilation?

In another study, 36 patients admitted to an emergency department were randomized to 3 treatment arms: medical therapy + nebulization, and 2 treatment groups with medical therapy + nebulization + NIV ${ }^{15}$. In the 2 NIV groups, inspiratory pressure was the same, while espiratory pressure was different ${ }^{15}$. The authors of this study noticed that only the group with lower espiratory pressure showed significant clinical improvement ${ }^{15}$.

Another observational uncontrolled study showed an improvement of BGA parameters, heart and respiratory rate after NIV in patient with severe asthma exhacerbations. We can find the same results in a study on pediatric patients. These studies suggest that in selected patients NIV may be useful as respiratory support for severe asthma. However, high power studies are lacking and in a Cochrane metaanalysis in 2005 just 1 of the 11 published studies satisfied inclusion criteria ${ }^{7,10}$.

We report a case of a patient admitted for a severe asthma exhacerbation, successfully treated with optimized medical therapy and NIV (zero-PEEP + pressure support). Even if anecdotical, it is not the first described in literature, because some authors described similar cases and some think that NIV may be effective in these patients ${ }^{6,7,8}$. Some studies agree with our hypothesis, but they are small-sized and with low statistical power ${ }^{15}$. If these data were confirmed, NIV could prevent endotracheal intubation almost in some selected patient, preventing ICU hospitalization and so decreasing morbidity and costs.

Despite that, it is not yet established if NIV could worsen dynamic hyperinflation. Besides, the higher airway resistance of asthmatic patient could make NIV difficult, forcing the physician to increase pressure support, so increasing also air losses and risk of barotrauma. Because of this point of uncertainty, and because of lacking evidence, NIV is not routinely recommended in severe asthma exhacerbations; however, the guidelines do not advise against its use $\mathrm{e}^{2,14}$. So, we can conclude that further studies are needed to clarify the role of non-invasive ventilation in asthmatic patients, patients selection criteria and timing compared to invasive ventilation.

\section{References}

1. Caples SM, Gay PC. Non invasive positive pressure ventilation in the intensive care unit: a concise review. Crit Care Med 2005; 33: 2651-2658.

2. Rodrigo GJ, Rodrigo C, Hall JB. Acute asthma in adults - a review. Chest 2004: 125; 1081-1102.

3. Brochard L, Mancebo J, Wysocki M et al. Noninvasive ventilation for acute exacerbations of chronic obstructive pulmonary disease. N Engl J Med 1995; 333: 817-822.

4. Plant PK, Owen JL, Elliott MW. Early use of non-invasive ventilation for acute exacerbations of chronic obstructive pulmonary disease on general respiratory wards: a multicentre randomised controlled trial. Lancet 2000; 355: 1931-1935.

5. Keenan SP, Sinuff T, Cook DJ et al. Which patients with acute exacerbation of chronic obstructive pulmonary disease benefit from noninvasive positive-pressure ventilation? A systematic review of the literature. Ann Intern Med 2003; 138: 861-870.

6. Ram FS, Picot J, Lightowler J et al. Noninvasive positive pressure ventilation for treatment of respiratory failure due to exacerbations of chronic obstructive pulmonary disease. Cochrane Database Syst Rev 2004; 1 CD004104.

7. Soroksky A, Stav D Shpirer I. A pilot prospective, randomized, placebocontrolled trial of bilevel positive airway pressure in acute asthmatic attack. Chest 2003; 123: 1018-1025.

8. Meduri GU, Cook TR, Turner RE et al. Non-invasive positive pressure ventilation in status asthmaticus. Chest 1996; 110: 767-774.

9. Thill PJ, McGuire JK, Baden HP et al. Noninvasive positive-pressure ventilation in children with lower airway obstruction. Pediatr Crit Care Med 2004, 5: 337- 342 .

10. Ram FS, Wellington S, Rowe BH, Wedzicha JA. Non-invasive positive pressure ventilation for treatment of respiratory failure due to severe acute exacerbation of asthma. Cochrane Database Syst Rev 2005; 20(3): CD004360

11. Medoff $\mathrm{BD}$. Invasive and noninvasive ventilation in patients with asthma Respir Care 2008; 53(6): 740-748.

12. Ranieri VM, Grasso S, Fiore T, Giuliani R. Auto-positive end-expiratory pressure and dynamic hyperinflation. Clin Chest Med 1996; 17(3): 379-394.

13. Tuxen DV. Detrimental effects of positive end-expiratory pressure during controlled mechanical ventilation of patients with severe airflow obstruction. Am Rev Respir Dis 1989; 140(1): 5-9.

14. Global Initiative for Asthma. A pocket guide for physicians and nurses, updated 2009 guidelines. http://www. ginasthma.org.

15. Brandao DC, Lima VM, Filho VG et al. Reversal of bronchial obstruction with bi-level positive airway pressure and nebulization in patients with acute asthma. J Asthma 2009; 46: 356-361.

16. Bourdon C, Camargo C, Bretzlaff J et al. Intravenous magnesium sulfate treatment for acute asthma in the emergency department: a systematic review of the literature. Ann Emerg Med 1999; 36: 181-190.

17. Koepsell T, Alter H, Hilty W. Intravenous magnesium as an adjuvant in acute bronchospasm: a meta-analysis. Ann Emerg Med 1999; 36: 191-197.

18. Rodrigo G, Rodrigo C, Burschtin O. Efficacy of magnesium sulfate in acute adult asthma: a meta-analysis of randomized trials. Am J Emerg Med 2000; 18: 216-221

\section{ABSTRACT}

Asthma is a chronic inflammatory disease affecting small airways, associated with

hyperresponsiveness, reversible airflow-limitation and respiratory symptoms. During

exhacerbations, the symptoms severity may vary from mild dyspnea to fatal status asthmaticus.

Non-invasive ventilation is a respiratory support method that in COPD has been used succesfully in the last
20 years; there is an increasingly interest about using non-invasive ventilation also in asthmatic patients. However, its role in status asthmaticus has not been yet established. In this article we report a case of a patient succesfully treated with non-invasive ventilation and we also review the literature about non-invasive ventilation in acute asthma 